\title{
NUCLEAR DIVISION IN SPIROGYRA CRASSA
}

M. L. MERRIMAN

(WITH PLATES XI AND XII)

Although the cytology of Spirogyra has been investigated probably more than that of any other alga, it still offers a fruitful field of inquiry. The varying accounts, beginning with STRASBURGER'S paper in $\mathrm{I} 882$ as to the chromatic or non-chromatic nature of the parts of the nucleus and the rôle they play in karyokinesis, have left many questions open.

$S$. crassa was chosen for this investigation on account of the large size of the nuclei, spindles of which can be detected with a magnifying glass. Specimens were fixed in weaker chromacetic, Flemming, and Bouin mixtures. Sections were cut $3-5 \mu$ in thickness. When spindles of the metaphase were sectioned, $3-5$ sections of one spindle were obtained. The stains used were safranin and gentian violet, Heidenhains hematoxylin with iron alum. Extended observations upon other species with smaller nuclei, but more easily studied in the living cells because of their greater transparency; have aided in making the interpretations given in this paper. In order to interpret sections of the large nuclei of $S$. crassa more satisfactorily, nuclei in different stages of division were also dissected from the filaments and from them whole mounts made. This dissection was necessary as nuclei in $S$. crassa are surrounded by a substance ramifying in the cell and so rendering them somewhat opaque. This condition, as well as that of their being obscured by the close winding of the chromatophores, prevented the adequate study of their division in the living cells.

In the living cells and in the mounted specimens three membranes can be distinguished clearly, one surrounding a central dense spherical body, a second surrounding a less dense larger body containing the first, and lastly a third which is continuous with the suspensors which in turn are continuous with the cord on which Boubier (3) has demonstrated the pyrenoids are dependent. These 3ro]

[Botanical Gazette, vol. 56 
membranes when not easily seen in the living cells were readily demonstrated by the use of methylene blue.

The initiation of division is marked by the enlargement of the nucleus and the gathering of granules in a vertical plane about the nucleus in the short axis of the cell. A study of the nucleus at this stage reveals great variations in the appearance of the central body, the so-called nucleolus, and the surrounding part, nuclearplasm. The periphery of the enveloping portion may consist of a fine network, the interstices of which are occupied by coarse or fine granules (fig. 5). Or in place of the granules a deeply stained but vacuolar material may form the junction of the threads (figs. I, 2, 4). This vacuolar-like material seen at the junction of the threads is in appearance like that seen in the chromosomes in late metaphase and anaphase. It also resembles that seen in Allium, for here the material is likewise thickened at the corners, suggesting four granules inclosing a vacuole.

The central body may appear from the staining to be of uniform density (figs. I, 2, 3), or it may be more or less vacuolar (fig. 4). In a later stage the central body may appear to disintegrate into deeply stained granules, while in the meantime the network becomes coarser and accumulations at the interstices of the deeply stained material more pronounced. This at times may consist of filamentous (fig. 3) instead of granular or vacuolar masses, hence tending to support GRÉGOIRE'S view (8) that there is no strict morphological distinction between chromatic granules and an achromatic substratum, and that in nuclei both an alveolar and reticular structure may obtain. These variations are due doubtless, as Digby (5) suggests in Galtonia, to the colloidal nature of the chromatic substance.

As the central body disintegrates (fig. 6), the space about it becomes gradually clearer, coincident with the expansion of the central mass which now occupies several times the original space. The fact that the space previously occupied by the network becomes clear, leads to the conclusion that network and nucleolus have become centralized in the spherical mass (figs. 7 and 8) now consisting of granules and filaments of varying dimensions irregularly disposed. All observers of nuclear division in Spirogyra are 
practically unanimous in the view that the nucleolus is partly or wholly transformed into the substance of the spindle; the disagreement is as to whether the network furnishes any of that substance. The chromatic nature of this network is shown in figs. 2 and 3 .

The nuclear membrane still intact shows that as yet none of the bodies previously seen in the space has been cast into the cytoplasm, unless in solutes by diffusion. This was confirmed by the study of whole mounts (fig. 8). Hence we may conclude that the enlargement of the central mass is due to the inclusion of the substances of the network, all now showing an increased staining capacity. It is possible, as in fig. 6 , where short filaments are seen distributed throughout the nucleus and superimposed on the central mass, that the latter as it disintegrates only contributes the granular material to the spindle.

With the enlargement of the central mass the evolution of the spindle proceeds. The suspensors increase in size, while streams of granules appear to penetrate the nuclear membrane and connect with the centrally lying mass (fig. 7). These later increase as the mass of chromatic material changes its shape from that of a sphere (figs. 6-8) to a cylinder (figs. I3-I6). Now the streams of granules appear to cause the cylinder to swing so as to lie with its long axis parallel with the long axis of the cell. In the fully developed spindle nothing of a fibrous nature is to be perceived but lines of granules staining as the cytoplasm, and so always distinguished from the equatorial mass. These lines of granules terminate in granular masses not linearly arranged. The masses are later seen to envelop the daughter nuclei (figs. 34, 36).

In sections of late prophase two kinds of material, one staining more deeply than the other, can be seen occupying the nuclear space, the nuclear membrane still visible. The more deeply stained material is in the form of short filaments (fig. I2) or lumplike masses (figs. I3, I5). The chromatic material here with its dumbbellshaped (figs. I3, I9, 20) or somewhat elongated granules often resembles that seen in precipitates secured by FISCHER when nuclein acid is precipitated with Flemming and chromic acid mixtures $(7$, p. 43). Also they may be reasonably compared with those in 
fig. $2(7$, p. 34$)$, secured when 20 per cent albumose is precipitated in a concentrated aqueous solution of sublimate. FischER has figured both of these bodies of unequal staining capacity, precipitated from the same substance and appearing as stages in division. The fact that they are secured by precipitation might indicate that in Spirogyra we have a similar case. The dumbbell-shaped bodies seen frequently in the centrally lying mass may be but stages in aggregation and not the beginning stages of division. They are probably the bodies described by BerGHS (I) and MItzGewitch (I2) as the chromosomes, although in the species studied by these writers I2 chromosomes were found. As in $S$. crassa they are variable as to number and shape and in all cases far exceed the number of chromosomes heretofore ascribed to Spirogyra, there seems to be justification for considering them not chromosomes, but rather amorphous masses of chromatin material which will serve as centers for the absorption of the less dense surrounding material.

FISCHER (7) found that nuclein acid granules, as they did not become corroded by iron alum, could be stained only a light smoke gray with aqueous hematoxylin, but when inclosed in deuteroalbumose solution their aversion to corrosion by alum salt was overcome. This suggests that the clue to the difference in the staining capacity of the component parts of the central mass may be sought in analogous changes in the composition of the colloids.

Although both kinds of material, ordinarily in the form of a spherical mass, nearly fill the nuclear space, in nuclei fixed with Bouin's mixture this was not found as frequently as the condition where the nuclear space is filled with irregularly shaped bodies undifferentiated as to stain.

With the elongation of the nucleus, the nuclear membrane first dissolves at the longer axis where the protoplasm condenses. The mass of material now gradually condenses, changing from spherical to cylindrical, the deeply stained material accumulating more along the central axis, Here it may be seen to be composed of oblong bodies, when filaments are arranged so as to be seen endwise (fig. I7), or as filaments somewhat intertwined. In all cases an areolar space marks off the entire spherical mass from the spindle. The darker stained bodies are also distinguished from the others by 
areolae. These bodies may be considered but as centers of condensation, where by absorption the finer granular matter is transformed to the denser state. The areola around the denser bodies, as well as that around the entire mass, may be of no morphological significance, as Fischer (7) obtained, when staining precipitates of deutero-albumose, all stages between a deeply stained central point and an areola of perceptible diameter.

It was not until drawings had been made of the thin sections and until the second year of this investigation that it occurred to me to make whole mounts of the dissected nuclei. These presented so different an appearance from the thin sections as to warrant an entirely different interpretation of the stages which show striations of granules and longitudinal arrangement of the deeply stained bodies. When such nuclei in stages just before and up to the complete dissolution of the nuclear membrane are examined, a continuous spireme including both kinds of material can be seen distinctly (fig. 9). The coils of this spireme are connected by anastomosing bridges. The deeply stained bodies, which seemed irregularly disposed in the thin sections (figs. Io, I3), in the whole mounts appear to lie with the granules in a spireme; a spireme, hence, not homogeneous, but consisting of material longitudinally arranged and of varying density, representing the pachyneme stage described by investigators on other plants.

This spireme, however, appears to be not greatly dissimilar to that seen in Allium in the prophase. In Allium there was more regularity in the arrangement of the chromatin masses and linin forming the spireme. In Spirogyra (fig. II) also an apparent longitudinal division of the spireme is present. This parallelism of the threads has been described by DigBy (5) in Galtonia. In Trillium, GRÉGOIRE (8) has interpreted it as an apparent splitting caused by progressive alveolization of the chromosomes; in Allium, BonNevie (2) has attributed similar appearances as due to the chromatin gathering at the peripheral portion of the chromosome, forming a spiral coil within; while the writer (Io) in Allium regarded the apparent split as the result of an aggregation of granules forming a quadripartite thread.

The great similarity of this spireme to that described by other 
writers is further evidence that in Spirogyra, as in Allium, we have here but a stage preparatory to the organization of chromosomes, and all bodies seen in preceding stages are but amorphous precipitates, their great variation being due to the colloidal nature of the chromatic substance. But slight pressure on the cover glass of these whole mounts appears to destroy the spireme appearances; the material then appears, as in sections, to consist of dark bodies and fine granules. These dark bodies sometimes appear as oblong granules. Examination of many slides and of some where the centrally lying material has been slightly displaced by the knife (fig. I7) indicates that the bodies appear oblong only because the filaments are seen endwise. There is nothing to indicate a definite number of these darkly stained bodies which appear to be homologous with those termed chromosomes by Mitzgewitch (I2), WisselINGH (I3), BERGHS (I), and others. Their appearance as lying in a spireme in whole mounts and their subsequent behavior in relation to the finer granular material show them to be, with the other material, but parts of the as yet unorganized chromosomes.

Returning to the study of the sections, we find a tendency of the deeply stained bodies to gather at the equatorial part of the cylinder in longitudinal rows (fig. I6). An illustration of this may be seen in the first section of a spindle, where both kinds of material show this longitudinal arrangement. A second section, cut deeper in the same spindle and so taking in less of the chromatic material, does not show such a bewildering array of bodies. Here the spireme formation can be seen as distinctly as in the case of the whole mounts. It is also in this stage that there can be seen a beginning of a trend of both kinds of material to the poles. This orientation of the chromatic material to the respective poles of the spindle, without the intervention of centrospheres, suggests that at this period in karyokinesis the chromatin masses may have acquired electrical charges, thus bringing about a state of mutual repulsion. A sharp split or rift along the equatorial circumference of the spindle does not appear, but instead, the interior (figs. 20-22) and then the equator (fig. 23) becomes gradually cleared of material. As this clearing proceeds, it is coincident with an amalgamation (figs. 23, 24) of the two kinds of material. Amalgamation when observed in 
living material appears to be due to the gradual loss of the more liquid portion streaming each side. This leaves the interior of the cylindrical-shaped spindle clear as amalgamation proceeds. When one looks down with low power upon a nucleus in this state, as in fig. 22, the mass appears to have separated, though no actual separation of the chromatic material has occurred; for use of higher power shows all the bodies still united in a spireme, although all the material has left the interior. Similar strepsinema stages in the whole mounts show that this amalgamated material is also in spireme formation (fig. 25), though no differentiation is to be seen but the line indicating its double nature. The general shape assumed by the spireme in its convolutions is flatter now than at the earlier stages. This flattening culminates in the elongation of its coils (fig. 26). As a result of these changes there is but one kind of material of intensive staining capacity, pointing to either pole. This amalgamation can be compared with that in Allium where the parallel threads made of granules fuse to form tubular chromosomes. In Spirogyra, as in Allium, the spireme evolves from substances of two staining qualities; in both, the amalgamated materials yield tubular chromosomes staining intensively with hematoxylin and anilin stains. Similar elongation of amalgamated filaments is shown by BERGHS (I). He did not observe a spireme, and as he terms the earlier indefinite deeply stained bodies the chromosomes, these amalgamated filaments he terms "pseudochromosomes." As their formation from irregular masses of chromatin by absorption and condensation proceeds to an organized spireme behaving in its entirety as the spiremes in Allium that segment into chromosomes, it is difficult to see why these amalgamated substances should be called "pseudochromosomes."

These coils of the spireme, now completely on the peripheral part of the cylinder, pull apart (figs. 26, 27). A definite transverse splitting does not appear, but instead there is a gradual elongation and constriction as of viscid masses. At last, attenuation brings about a separation of the chromatic strands, not at any definite dividing line, but at various points in the spireme. This was confirmed in the study of living, dividing nuclei of a more transparent species of Spirogyra. Further evidence that the spireme ruptures 
at different points is to be found in the fact that chromosomes, as in fig. 26 , are often stretched across, when most of the material is already near the poles. As they separate, the chromosomes are connected by an anastomosing network (fig. 30), a beginning of that seen in the developed daughter nuclei. Often, if not always, strands are left after the assembling of the chromosomes at the poles. These chromatic masses persist in the cell after the membranes of the daughter nuclei are formed. As they can be traced step by step to the chromatic material of the metaphase, they may rightfully be termed chromidia and not considered metabolic products deposited in the cytoplasm. Their frequent occurrence at this stage of division suggests that the casting out of such masses may be a normal phenomenon, and that these chromidia are active in the secretory or other functions of the cell.

Derschau (4) observed in the leaf epidermis cells of Berberis chromatin protuberances from the nucleus beginning to turn green. He considers them chromidial substances laying the foundation of the chloroplasts. LEwITSKy also holds that the chromatophores develop from chondriosomes, although MEYER (II) considers his conclusions unsound, as his investigations led him to believe that chromatophores arise only through the division of other chromatophores. FARMeR and DigBY (6) describe in certain varietal and hybrid ferns the ejection from nucleus into cytoplasm of chromatic droplets during early stages of heterotypic mitosis and also during telophase. Future research may likewise connect in Spirogyra these chromidia with the origin of chromatophores and pyrenoids.

As the chromosomes elongate and assemble at the poles, a split lengthwise can be seen in each, in some more definitely than in others (figs. 28-30). Sections cut obliquely (fig. 27) show the tubular or hollow formation of the chromosomes; those cut transversely, the ringlike nature resolving later into the four thickened masses inclosing a vacuole. The number of these chromosomes could not be ascertained definitely, but it seemed to approximate I4, more rather than less. This would correspond with that found by KARSTEN (9) in Spirogyra jugalis.

As the chromosomes near the poles they become V-shaped (fig. 33). When condensation has sufficiently proceeded, the ma- 
terial is seen to assemble more at the ends of the double V's, thus presenting the appearance of tetrads (fig. 28). The V-shaped chromosomes represent but the loops or portion of the loops of the original spireme now ruptured. Each $V$ has the characteristic line as seen in the original spireme, showing it to consist of parallel threads of chromatin. The more deeply stained ends of the loop are homologous with the structures described by BERGHS (I) as the true chromosomes reappearing from the mass of "pseudochromosomes," an interpretation which seems unwarranted when their whole history is taken into consideration.

After rupture of the spireme, the chromosomes do not form daughter spiremes, but joined by anastomosing bridges of linin cohere loosely in a ring or disk (fig. 32, 33). These figures are not dissimilar to those of GRÉGOIRE (8) in Trillium, where each of anastomosed chromosomes after polar assemblage becomes by alveolization an elementary reseau, at once of an alveolar and reticular nature. The chromosomes in the ring or disk gradually shorten their loops, and approach each other more closely until a confluence of the chromatic material results in one to several vesicular masses (figs. 35, 36) lying within a granular material that formerly was at the ends of the spindle and into which the chromatin retreated. These masses are crossed by cavities, spherical or polyhedral. At this time the chromatic masses are surrounded by a clear space, around the margin of which the nuclear membrane begins to evolve (fig. 37).

\section{Summary}

A summary of the results obtained that differ most from others published is as follows:

A spireme originates from material derived from both nucleolus and nuclear network. The materials constituting this spireme are aggregations varying in appearance, in number, and in staining capacities.

These aggregations are not the chromosomes. They greatly exceed in number that published for chromosomes in any species of Spirogyra; although a comparative study of plates of other 
investigators indicates that these are the bodies heretofore designated as chromosomes.

This spireme in the pachyneme stage is composed of deeply stained short filaments intermixed with material of a granular nature. There is evidence that this granular material was derived from the nucleolus, the filamentous from the nuclear network.

These two materials amalgamate to form one of intensive staining capacity. The amalgamated material retains the spireme form. This spireme as a whole is spherical, later elongates, becoming cylindrical. Cross-sections of the loops reveal their tubular structure.

This spireme does not appear to split either transversely or longitudinally, but separates at various points as would a viscid mass if pulled in opposite directions. Fourteen or more tubular chromosomes for each daughter nucleus result from the elongation of the coils of the spireme. These are not to be considered "pseudochromosomes."

At this stage and subsequently chromidia are discharged into the cytoplasm. It is probable that these chromidia are concerned in the development of pyrenoids.

There is no evidence throughout the karyokinesis of an equational division of autonomous bodies. The advantage of this form of division over direct divisions appears to lie in the opportunity for escape of the chromidia from the nucleus.

Spirogyra crassa does not in the behavior of its nucleus in karyokinesis present a unique case, for the stages can be homologized with similar stages in Allium, as typical of the higher plants.

Normal College

New YoRk City

\section{LITERATURE CITED}

I. Berghs, J., Le noyau et la cinèse chez le Spirogyra. La Cellule 23: 55-86. pls. I-3. 1906 .

2. Bonnevie, K., Chromosomenstudien I. Archiv. Zellforschung I:4505I 5. I908. Chromosomenstudien II. Ibid., 2:20I-278. I909.

3. Boubier, A.M., Contributions à l'étude du pyrénoide. Bull. Herb. BoISSIER 7:45I-458, 554-559. I899. 
4. Derschau, M., Zur Frage eines Makronucleus der Pflanzenzelle. Archiv. Zellforschung 4:254-264. figs. 8. I910.

5. Digby, L., Somatic, premeiotic, and meiotic nuclear divisions of Galtonia candicans. Ann. Botany 24:727-757. pls. 49-53. I910.

6. FARMer, J. B., and DigBY, L., On cytological features exhibited by certain varietal and hybrid ferns. Ann. Botany 24:I9I-2I3. pls. I6-I8. I9Io.

7. Fischer, A., Fixirung, Färbung, und Bau des Protoplasmas. Jena. I899.

8. GRÉGoIRE. V., Le reconstitution du noyau et la formation des chromosomes dans les cinèses somatiques. La Cellule 2I:7-76. pls. I, 2. 1903 .

9. KarSten, G., Die Entwicklung der Zygoten von Spirogyra jugalis. Flora 99: I-II. pl. I. I 908.

I0. Merriman, M. L., Vegetative cell division in Allium. Bot. Gaz. 37:178207. pls. II-I 3. I904.

II. Meyer, A., Bemerkungen zur G. Lewitsky: Über die Chrondriosomen in pflanzlichen Zellen. Ber. Deutsch. Bot. Gessells. 29:158-r6o. I9r I.

I2. Mrtzgewitsch, L., Über die Kerntheilung bei Spirogyra. Flora 85:8II24. $p l$. I. I 898 .

13. Van Wisseldingh, C., Über Kerntheilung bei Spirogyra. Flora 87:355. I900.

\section{EXPLANATION OF PLATES XI AND XII}

All figures were sketched with an Abbé camera. The nuclei were stained with Heidenhain's hematoxylin and iron alum, or with safranin and gentian violet.

FIGS. I-7.-Sections representing changes in nucleolus and nuclear network up to the invasion of the spindle fibers; nuclei fixed in Bouin fluids (figs. I, 6), in chromacetic (figs. 2, 3, 5, 7), in Flemming (fig. 4); Leitz oc. 4 and I/ I 2 oil im.

FIGS. 8, 9.-Nuclei dissected from filaments and mounted without sectioning; fixed in chromacetic; Zeiss comp. oc. 12 and Leitz I/ 22 oil im.

FIG. 10.- Section of stage similar to that in fig. 9; same fixing and magnification.

FIG. Ir.-Whole mount of nucleus at later stage than in fig. 9; only central portion drawn to show change in shape of spireme; Leitz oc. 4 and I/I 2 oil im.

FIG. I2.- Section of stage similar to that in fig. Ir ; fixed in Flemming; Zeiss comp. oc. I2 and Leitz obj. 6.

FIGs. $\mathrm{I}_{3}-\mathrm{I} 6$. -Figs. $\mathrm{I} 3$ and $\mathrm{I} 6$ fixed in chromacetic, figs. $\mathrm{I}_{4}$ and $\mathrm{I} 5$ in Flemming; Leitz oc. 4 and I/r 2 oil im.

FIG. I7.-Section fixed in chromacetic, in which some filaments are dislodged by knife; Zeiss comp. oc. 12 and Leitz obj. 6 .

FIG. I8.-Section cut obliquely; fixed in Flemming; Leitz oc. 4 and obj. 6.

FIGS. I9-24. -Sections fixed in chromacetic (figs. 19, 20, 23, 24) and in Flemming (figs. 21, 22); Zeiss oc. 6 and Leitz I/r2 oil im. 
FIG. 25.-Whole mount of stage similar to that in fig. 24; Zeiss oc. I2 and Leitz obj. 6.

FIGs. 26-31.-Sections fixed in chromacetic (figs. 26, 27, 31) and in Flemming (figs. 28, 29, 30); Leitz oc. 4 and I/I2 oil im.

FIG. 32.-Whole mount, showing somewhat polar views of disks of chromosomes; Zeiss oc. I2 and Leitz obj. 6.

FIGS. 33-37.-Sections fixed in Bouin fluid (fig. 33), in Flemming (fig. 35), in chromacetic (figs. 36,37 ); also a whole mount (fig. 34); Leitz oc. 4 and I/I2 oil im. 

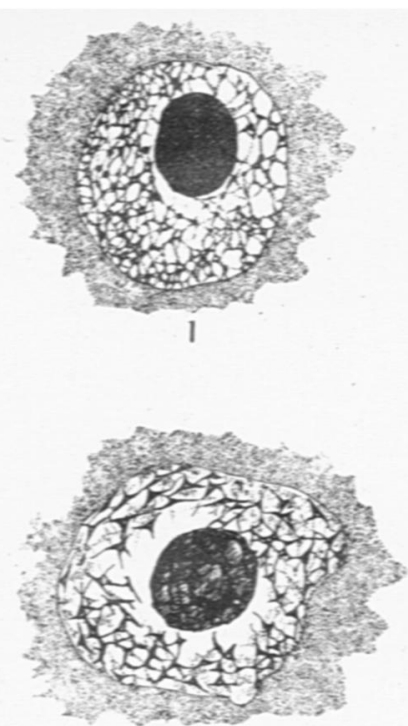

4

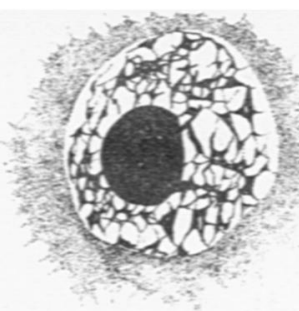

2

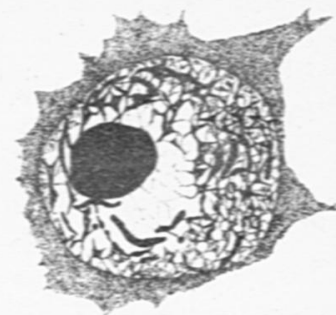

3

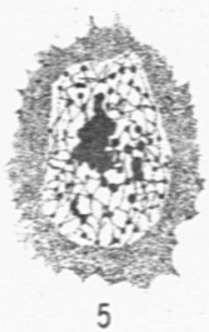

5

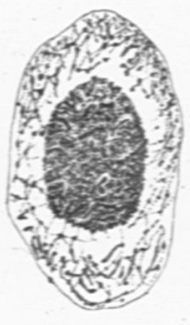

6

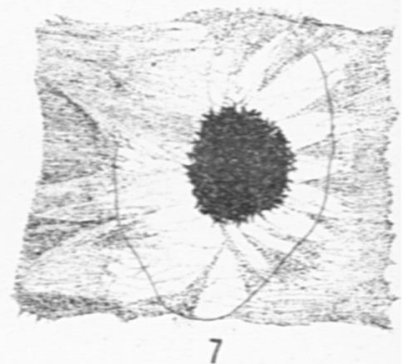

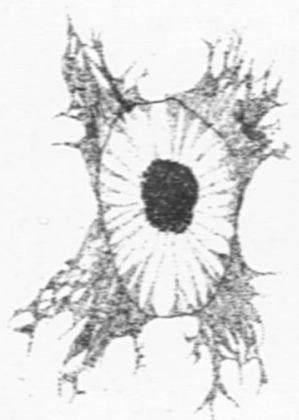

8

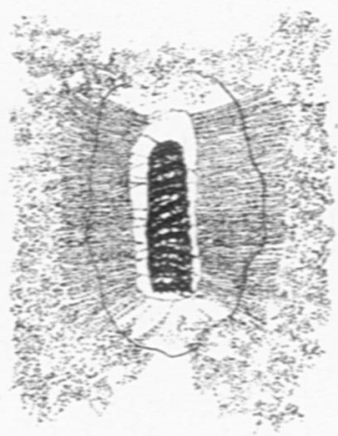

9

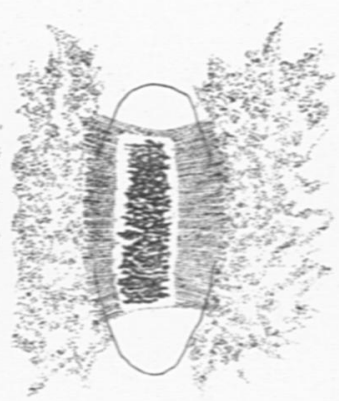

10

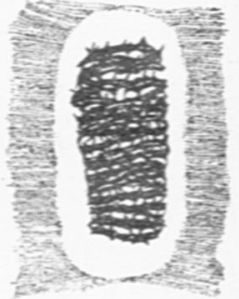

11

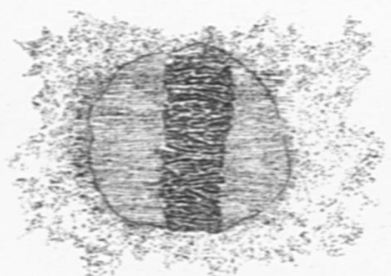

12

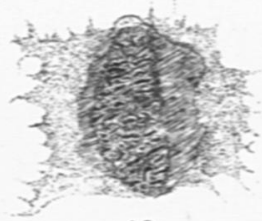

13

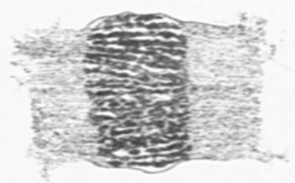

14

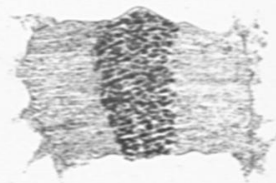

15

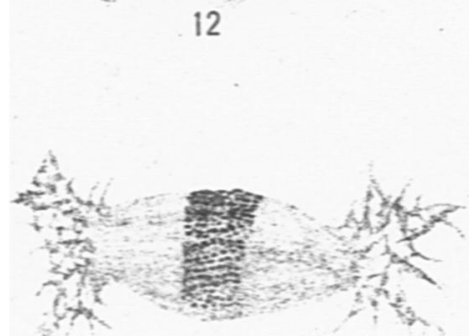

16

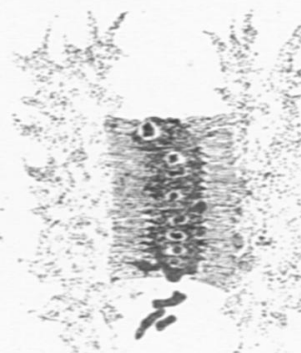

$+17$

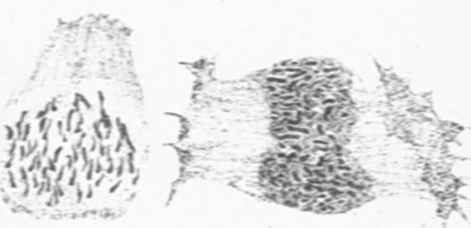

18

19

\section{MERRIMAN ON SPIROGYRA}




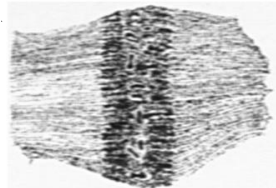

20

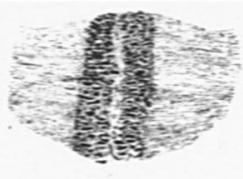

21

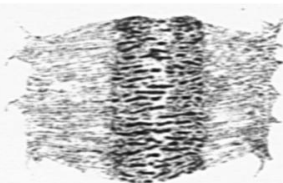

22

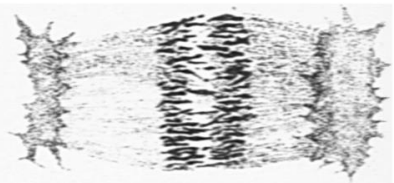

23

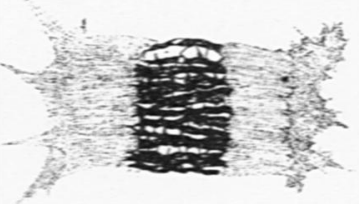

24

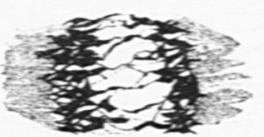

27

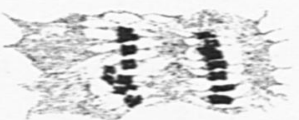

28

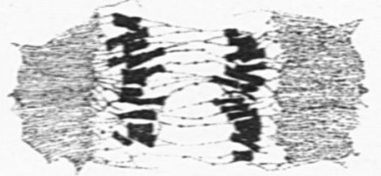

29

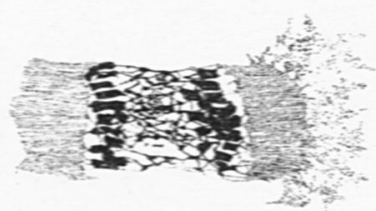

30

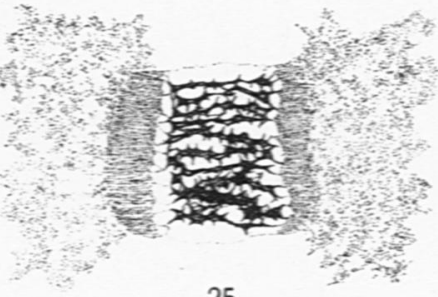

25

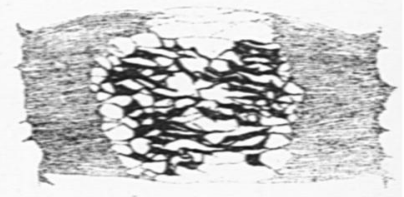

26

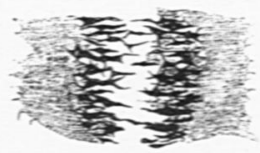

31
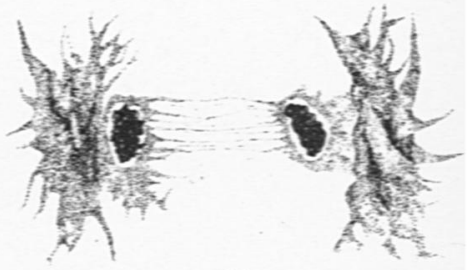

34

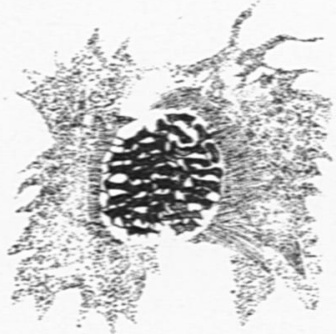

32

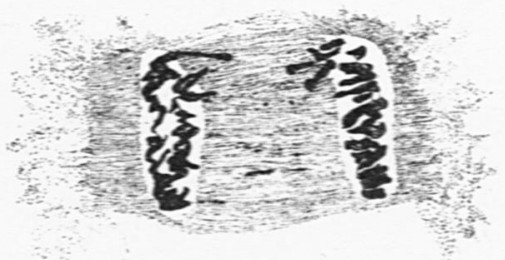

33

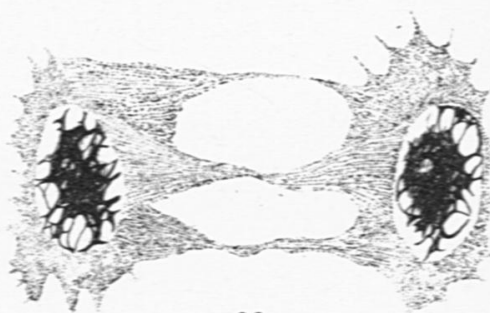

36

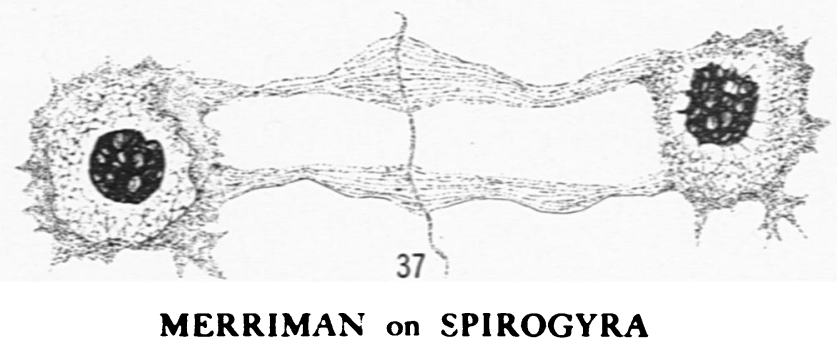

This content downloaded from 080.082.077.083 on February 19, 2018 18:47:45 PM

All use subject to University of Chicago Press Terms and Conditions (http://www.journals.uchicago.edu/t-and-c). 